\title{
Variação estacional da oferta e preços de couve-flor em Minas Gerais
}

\author{
Luis Felipe Lima e Silva ${ }^{1}$, Wilson Roberto Maluf ${ }^{2}$, Wilson Magela Gonçalves ${ }^{3}$, Luciane Vilela Resende ${ }^{4}$, \\ Regis de Castro Carvalho ${ }^{5}$, Christiany Mattioli Sarmiento ${ }^{6}$
}

\section{RESUMO}

Em virtude da variedade de cultivares atualmente disponíveis, de suas diferentes exigências climáticas e das diferenças climáticas entre as várias regiões produtoras, a couve-flor pode apresentar variações estacionais de oferta e de preços ao longo do ano. O objetivo do presente trabalho foi estudar a variação estacional da oferta e dos preços da couve-flor praticados no Estado de Minas Gerais, representados pelas unidades da CEASAMINAS, bem como as componentes dessa oferta para cada principal região abastecedora do Estado, no período de 2005 a 2009. A unidade CEASAMINAS (Grande BH) foi responsável por $68 \%$ da comercialização anual de couve-flor em Minas Gerais por meio das unidades da CEASAMINAS, que oscilou entre 9.420 e 10.937 toneladas anuais. A quase totalidade de produção proveio de municípios mineiros, localizados em quatro grandes mesorregiões: Região Metropolitana de Belo Horizonte, Campo das Vertentes, Triângulo Mineiro e Vale do Rio Doce, que representaram, respectivamente, 49\%, $28 \%, 9 \%$ e $6 \%$ da oferta anual. As variações estacionais de oferta refletiram claramente as limitações dos cultivares atualmente disponíveis e a necessidade de novos cultivares que possam tolerar as grandes oscilações de temperatura nos meses de meia estação. Também ficou evidente que, a despeito da disponibilidade de cultivares de verão, a produção de couve-flor ainda é mais baixa nessa época do ano, um reflexo provável da alta precipitação que ocasiona maiores perdas por doenças na lavoura e em pós-colheita.

Palavras-chave: Brassica oleracea var. botrytis, variação estacional, cultivo, oferta, preço.

\section{ABSTRACT}

\section{Seasonal variation of supply and prices of cauliflower in the state of Minas Gerais, Brazil}

Due to the large number of varieties currently available, their different climatic requirements and different climates among producing regions, cauliflower may have seasonal variations in supply and price throughout the year. The objective of this work was to analyze the seasonal variation of supply and prices of cauliflower in the State of Minas Gerais (as indicated by the wholesale terminal market CEASAMINAS-Belo Horizonte), as well as the contribution of the main cauliflower producing regions in the State to the total supply, from 2005 to 2009. The wholesale terminal market CEASAMINAS-Belo Horizonte accounted for $68 \%$ of the total yearly commercialization of cauliflower through the different units of the CEASAMINAS system, which varied between 9420 and 10937 metric tons per year. Almost all of the total production originated from within-state municipalities, located in four major producing regions - Metropolitan

Recebido para publicação em 14/12/2012 e aprovado em 06/09/2013.

${ }^{1}$ Engenheiro-Agrônomo, Mestre. Departamento de Agricultura, Universidade Federal de Lavras, Rua Padre Bernardo Kowner, 50, Bairro Padre Dehon, 37200-000, Lavras, Minas Gerais, Brasil. luisufla@hotmail.com (autor para correspondência).

${ }^{2}$ Engenheiro-Agrônomo, PhD. Departamento de Agricultura, Universidade Federal de Lavras, 37200-000, Caixa Postal 3037, Lavras, Minas Gerais, Brasil. wrmaluf@dag.ufla.br ${ }^{3}$ Engenheiro-Agrônomo, Doutor. Departamento de Agricultura, Universidade Federal de Lavras, 37200-000, Caixa Postal 3037, Lavras, Minas Gerais, Brasil. magela@ dag.ufla.br ${ }^{4}$ Engenheiro-Agrônoma, Doutora. Departamento de Agricultura, Universidade Federal de Lavras, 37200-000, Caixa Postal 3037, Lavras, Minas Gerais, Brasil. luciane.vilela@dag.ufla.br

${ }^{5}$ Engenheiro-Agrônomo. Mestrando no Departamento de Biologia, Universidade Federal de Lavras. 37200-000, Praça Dona Josefina, 196, Centro, Lavras, Minas Gerais, Brasil. regisccarvalho@hotmail.com

${ }^{6}$ Geógrafa. Mestranda do Departamento de Engenharia, Universidade Federal de Lavras, Rua João Pomarico, 279, Bairro Padre Dehon, 37200-000, Lavras, Minas Gerais, Brasil. chrislavras@yahoo.com.br 
Region of Belo Horizonte, Campo das Vertentes, The Minas Triangle Region, and the Rio Doce Valley, accounting for $49 \%, 28 \%, 9 \%$ and $6 \%$ of the total yearly supply, respectively. Variation in the seasonal supply clearly reflected the limitations of the currently available cultivars and evidenced the need for new cultivars that could withstand wider temperature ranges during seasonal transitions. In spite of the availability of heat-tolerant cauliflower cultivars, the supply is lower during the summer, a possible consequence of the high rainfall during this season, which can cause losses due to high disease incidence in the field and in the post-harvest period.

Key words: Brassica oleracea var. botrytis, seasonal variation, cultivation, supplies, prices.

\section{INTRODUÇÃO}

A couve-flor, uma hortaliça conhecida e consumida mundialmente, pertence à família das Brassicaceae, a mesma do repolho, couve-comum, brócolos, entre outros. É descendente da couve-selvagem, originária da costa do Mar Mediterrâneo (Filgueira, 2003). O produto comercial da couve-flor é conhecido como cabeça, e consiste de uma massa de pré-inflorescências, disposta de maneira compacta. No Brasil, a introdução dessa hortaliça se deu principalmente com a vinda dos primeiros imigrantes italianos, sendo mais cultivada nos Estados de São Paulo, Rio de Janeiro, Rio Grande do Sul, Minas Gerais, Paraná e Santa Catarina. Essa cultura tem também grande importância para os agricultores familiares, que normalmente cultivam pequenas áreas com essa espécie ao longo do ano. É uma cultura lucrativa e bastante exigente em mão de obra, principalmente na fase de colheita (May et al., 2007).

A escolha do material genético tem papel crucial nos resultados que se deseja alcançar no sistema produtivo. A couve-flor é uma planta exigente no que se refere ao clima. Os primeiros cultivares disponíveis somente se adaptavam às condições amenas e de inverno, de modo que geralmente as principais regiões produtoras situavam-se no centro-sul do País, em locais de clima mais ameno.

Em virtude da variedade de cultivares atualmente disponíveis, de suas diferentes exigências climáticas e das diferenças climáticas entre as várias regiões produtoras, a couve-flor pode apresentar variações estacionais de oferta e de preços ao longo do ano. No Brasil, são escassos os estudos que retratam os aspectos econômicos relativos à oferta, comercialização e preços de couve-flor. É de grande importância disponibilizar aos produtores, atacadistas e consumidores as informações da comercialização e as principais tendências do processo produtivo (Camargo-Filho et al., 1994). Os diferentes cultivares são classificados, segundo a época ideal para semeadura, em de inverno e de verão/meia-estação. Essa classificação considera a necessidade de frio para a formação de cabeça em cada material. Predominam atualmente cultivares híbridos de couve-flor que têm como vantagens, comparados aos cultivares de polinização aberta, maior uniformidade de produção, maior resistência às oscilações bruscas de temperatura e formação de cabeças maiores e de melhor qualidade. No Brasil, quase a totalidade dos produtores profissionais de couve-flor utilizam sementes híbridas para a produção (Maluf, 2001), e mesmo com a adoção desses cultivares ainda são observadas significativas variações nos índices estacionais de sua produção. As variações estacionais de uma série temporal de preços apresentam normalmente comportamento comum nos mesmos meses em anos sucessíveis, visto que esse comportamento pode ser alterado por eventos casuais como mudanças climáticas atípicas e incidência de pragas e doenças (Spiegel, 1993; Machado et al., 2008).

As respostas dos principais cultivares de couve-flor variam conforme as condições de temperatura prevalecentes nas diferentes regiões produtoras e, por afetarem marcadamente a oferta do produto, podem ser responsáveis por significativa variação estacional de preços. A falta de conhecimento dos índices econômicos de mercado como as variações estacionais de preços e ofertas pode levar os produtores a um retorno econômico inferior ou até mesmo à perda total da produção (Luengo \& Junqueira, 1999). Em se tratando da oferta de um produto agrícola, a causa básica para as variações sazonais são as mudanças observadas no clima relacionado às diferentes estações do ano (Francisco et al., 1995). O mercado de hortaliças apresenta estacionalidade marcante, em nível de produção, causada por grandes oscilações de oferta e de preços. Conhecendo-se a demanda por época de uma hortaliça, pode-se realizar um planejamento de produção detalhado, o que poderá resultar em significativos ganhos econômicos (CamargoFilho \& Mazzei, 1994).

Para se proporcionar melhor retorno econômico ao agricultor e preços mais estáveis ao consumidor, devemse identificar os principais problemas apresentados pelos mecanismos e organizações do sistema produtivo (Rezende et al., 1993). Para isso, é fundamental ter-se o 
conhecimento de todo processo de comercialização, identificando-se os principais canais e relações entre os agentes envolvidos em cada etapa.

De acordo com Carvalho et al. (2008), é fundamental obter-se o conhecimento das flutuações periódicas de produção e de preços para a correta análise da atividade econômica dos produtos alimentícios. Hoffmann (1991) ressalta sobre a importância do conhecimento da variação estacional dos preços na orientação dos produtores rurais, comerciantes, consumidores, bem como para a formulação de políticas agrícola governamentais. Estudos sobre o comportamento sazonal de espécies agrícolas são importantes fontes de pesquisa para a análise de séries temporais de produção e de preços (Francisco et al., 1995). O conhecimento do comportamento de preços de uma olerícola é um dos aspectos mais importantes para a obtenção de adequada rentabilidade econômica na cultura (Araújo et al., 1999). A análise conjunta de todos os dados de produção e oferta da couve-flor poderá servir como base para planejamentos da produção dessa cultura em diferentes regiões de climas semelhantes, ou para regiões que apresentem potencial como futuras produtoras.

A comercialização da couve-flor em Minas Gerais ocorre principalmente nas centrais de abastecimento do CEASAMINAS, que compreendem as seguintes unidades regionais: Grande $\mathrm{BH}$ (Belo Horizonte), Barbacena, Caratinga, Governador Valadares, Juiz de Fora e Uberlândia.

O objetivo do presente trabalho foi estudar a variação estacional da oferta e dos preços da couve-flor praticados no Estado de Minas Gerais, representados pela CEASAMINAS, bem como as componentes dessa oferta para cada principal região abastecedora do Estado, no período de 2005 a 2009. Como as variações estacionais de preços são muitas vezes ligadas a um padrão de comportamento comum nos mesmos meses em anos sucessivos (Spiegel, 1993), o estudo irá disponibilizar índices das variações estacionais de oferta, demanda e de preços que poderão ser utilizados para a tomada de decisões do manejo da produção, organizando o sistema produtivo de forma a obter os produtos em quantidade e qualidade almejadas.

\section{MATERIAL E MÉTODOS}

O estudo foi realizado a partir de dados de oferta e preços referentes à produção de couve-flor destinada às unidades da CEASAMINAS, dos anos de 2005 a 2009, disponibilizados na página do Ceasa Minas na Internet (www.ceasaminas.com.br, 2010). Os dados de oferta de couve-flor nas diversas unidades da CEASAMINAS (CEASAMINAS: Grande BH, Barbacena, Caratinga, Governador Valadares, Juiz de Fora e Uberlândia) foram totalizados e expressos em termos de porcentagem para cada unidade regional. Dados referentes aos principais municípios produtores e suas respectivas ofertas para todas as unidades do mercado da CEASAMINAS foram obtidos e agrupados segundo sua respectiva mesorregião geográfica em quatro grandes regiões produtoras, sendo elas: Metropolitana de Belo Horizonte, Campo das Vertentes, Triângulo Mineiro e Vale do Rio Doce. Os dados foram também processados pelo programa INDEVES (programa para cálculo de índices de variação estacional de preços, do Departamento de Economia e Sociologia Rural da ESALQ USP, 1987). O programa cria um arquivo de dados numéricos por meio da metodologia conhecida como média geométrica móvel centralizada. O resultado do procedimento é gravado num arquivo de saída, de onde se obtiveram índices mínimos, médios e máximos para a oferta total de couve-flor no conjunto de seis unidades da CEASAMINAS para os anos de 2005 a 2009, bem como para cada uma das regiões produtoras individuais.

O método da média geométrica móvel centralizada é indicado para calcular a estacionalidade de produção e de preços em forma de dados anuais ou bianuais; esse método é descrito por Hoffmann (1991). O primeiro passo do método consiste em calcular a média geométrica móvel centralizada (MGM) para cada mês da série de dados do período de meses/anos desejado. Assumindo-se como exemplo o mês de janeiro de 2006, tomando-se o logaritmo neperiano das médias de produção para o período, a MGM é dada por:

$\mathrm{MGM}_{\mathrm{jan} 2006}=\left(\ln \mathrm{P}_{\mathrm{jul} 2005} \mathrm{x} 0,5\right)+\ln \mathrm{P}_{\mathrm{ag} 02005}+\ldots+\ln \mathrm{P}_{\mathrm{jun} 2006}+\left(\ln \mathrm{P}_{\mathrm{jul} 2006} \mathrm{x} 0,5\right)$ 12

Sendo MGM a média geométrica móvel e $\operatorname{lnP}$ o logaritmo neperiano dos dados de produção referentes ao mês em questão, para o cálculo considera-se o dado de produção do mês (de janeiro, no exemplo) e os dos seis meses anteriores e dos seis meses posteriores, e o primeiro mês e o último (julho de 2005 e julho de 2006, no exemplo) são multiplicados por 0,5 , a fim de se obter o resultado referente a um período de 12 meses. Após os cálculos das médias geométricas móveis, são calculadas as diferenças entre o dado de produção de cada mês e sua média móvel. São calculadas também as médias dessas diferenças para cada mês do ano, resultando em valores médios de janeiro a dezembro, dos quais são computadas as médias aritméticas. Os resultados dos cálculos que não se igualam a zero são corrigidos, retirando-se de cada média da diferença mensal a respectiva média aritmética. Os índices sazonais são finalmente obtidos elevando-se os resultados à base do logaritmo neperiano e multiplicandose por 100. Para os cálculos dos índices de irregularidade (índices máximos e mínimos), inicialmente são calculados os desvios padrões para os resultados dos índices sazo- 
nais de cada mês e depois elevada a cada resultado a base do logaritmo neperiano. Esses números, quando multiplicados pelo índice sazonal obtido, resultaram nos índices superiores e quando divididos, nos índices inferiores. Os resultados foram apresentados em gráficos.

Seguindo a mesma metodologia, também foram obtidos os índices mínimos, médios e máximos de preços praticados na CEASAMINAS (Unidade Grande BH) durante o mesmo período, os quais foram tomados como representativos dos preços praticados no Estado. Dados de altitude média das principais regiões produtoras foram relacionados aos obtidos para suas respectivas variações estacionais de oferta, na tentativa de se explicarem tais variações à luz das possíveis respostas dos cultivares de couve-flor às características climáticas de cada região (CEPETEC/INPE, 2010).

\section{RESULTADOS E DISCUSSÃO}

A unidade CEASAMINAS (Grande BH) foi responsável por $68 \%$ da comercialização anual de couve-flor em Minas Gerais (Tabela 1) pelas unidades da CEASAMINAS e, portanto, os preços nela praticados são considerados representativos dos praticados para a comercialização de couve-flor no Estado.

A oferta total de couve-flor comercializada nas unidades da CEASAMINAS entre 2005 e 2009 oscilou entre 9.429 e 10.937 toneladas/ano, com média anual de aproximadamente 10 mil toneladas, e a quase totalidade de produção proveio de municípios mineiros (Tabela 1), tendo os municípios de Rio Manso, Barbacena e Itatiaiaçu representado $52 \%$ de toda a oferta de produção no respectivo período.

Os principais municípios de Minas Gerais responsáveis pela produção de couve-flor destinada às unidades da CEASAMINAS localizam-se em quatro grandes mesorregiões, sendo elas:

Região Metropolitana de Belo Horizonte - composta pelos seguintes municípios produtores: Igarapé, Rio Manso, Itatiaiuçu, São Joaquim de Bicas, Mateus Leme, Pedro Leopoldo, Jequitibá, Jaboticatubas, Brumadinho, Cordisburgo, Crucilândia, Ibirité, Caeté, Belo Horizonte, Santana de Pirapama, Paraopeba e Bonfim.

Campo das Vertentes - composta pelos municípios Barbacena, Carandaí, Alfredo Vasconcelos, Ressaquinha e Lagoa Dourada.

Triângulo Mineiro - composta pelos seguintes municípios produtores: Araguari, Indianópolis, Uberlândia, Patrocínio e Estrela do Sul.

Vale do Rio Doce - composta pelos seguintes municípios produtores: Ubaporanga, Santa Barbara do Leste, Piedade de Caratinga, Caratinga e Mutum.
Juntas, a Região Metropolitana de Belo Horizonte e a mesorregião Campo das Vertentes respondem pela maior produção de couve-flor ofertada para o CEASAMINAS, em média 77\%. O Triângulo Mineiro e Vale do Rio Doce representam conjuntamente $15 \%$ da produção total (Tabela 1).

O mercado da couve-flor em Minas Gerais é marcado por grande oscilação de oferta e preços durante o ano. Em média, a oferta no Estado (Figura 1) é menor de novembro a maio/junho, sendo fevereiro o mês de menor produção. Nesses meses, que compreendem os meses de maior temperatura e precipitação (dezembro a fevereiro), bem como os da meia-estação (final de verão/outono), a menor oferta do produto se reflete nos preços representados pelos praticados na CEASAMINAS (Grande BH), que são maiores nesa época (Figura 2). Por outro lado, os meses de maiores ofertas do produto vão de julho a setembro/outubro, principalmente de julho a setembro, período coincidente com o de temperaturas amenas e menores precipitações, situações mais favoráveis à produção da couveflor (Figura 1). Consequentemente, esse é também o período de menores preços na CEASAMINAS (Grande BH), que se apresentam bem abaixo da média anual nos meses de julho a setembro, principalmente (Figura 2).

Os períodos críticos para a produção de couve-flor em Minas Gerais variam de acordo com o clima de cada mesorregião. Consideram-se como críticos os períodos em que houve maior amplitude de variação de oferta entre os índices mínimo e máximo, ao longo do período de 2005 a 2009.

Tabela 1. Comercialização anual da couve-flor em cada um dos seis mercados regionais de comercialização da CEASAMINAS e sua precedência comercializada nas unidades da CEASAMINAS referentes aos anos de 2005 a 2009

\begin{tabular}{lc}
\hline \multicolumn{2}{c}{ Comercialização } \\
\hline Unidade & $\%$ \\
\hline Grande BH & 68 \\
Uberlândia & 10 \\
Juiz de Fora & 8 \\
Barbacena & 7 \\
Caratinga & 5 \\
Governador Valadares & 2 \\
\hline
\end{tabular}

Produção total no período 2005-2009 $\quad 52.376 .106$ kg

\begin{tabular}{lc}
\hline & Precedência \\
\hline Mesorregião & \% \\
\hline Metropolitana de BH & 49 \\
Campo das Vertentes & 28 \\
Triângulo Mineiro & 9 \\
Vale do Rio Doce & 6 \\
Outros & 8 \\
\hline
\end{tabular}

Oferta média anual $10.114 .000 \mathrm{~kg}$ 
Região Metropolitana de Belo Horizonte: A maior produção de couve-flor ofertada para todas as unidades da CEASAMINAS é observada nessa Região (Tabela 1), totalizando, em média, $49 \%$ da oferta total.

Ocorre menor oferta de couve-flor geralmente no período que vai de janeiro até maio (Figura 3), principalmente de março a maio, sendo abril e maio os meses nessa época com maiores variações de ano a ano, principalmente em maio, com amplitude de 60 pontos entre os índices mínimo e máximo. Esse período de menor oferta corresponde à transição de verão para outono, com temperatura mínima típica para essa região de $14^{\circ} \mathrm{C}$, média de $18^{\circ} \mathrm{C}$ e máxima de $24^{\circ} \mathrm{C}$.

Nos meses de setembro e outubro ocorrem as maiores produções médias, mas com grande variação de ano a ano, principalmente em setembro, quando a amplitude entre os índices mínimo e máximo foi de 63 pontos. Esse período de maiores produções corresponde ao início da prima- vera, com temperatura mínima típica de $16,5^{\circ} \mathrm{C}$, média de $20,5^{\circ} \mathrm{C}$ e máxima de $28^{\circ} \mathrm{C}$.

Ambos os períodos críticos corresponderam a períodos de meia-estação (transição verão/outono ou inverno/primavera). A altitude média dos municípios produtores é de 830 metros, o que ocasiona marcadas variações de temperaturas entre noite e dia e também de ano a ano, nessas épocas, e pode explicar as grandes variações de produção de um ano para outro.

Campo das Vertentes: Essa mesorregião está em $2^{\circ}$ lugar em quantidade de oferta de couve-flor para as unidades da CEASAMINAS (Tabela 1), totalizando, em média, $28 \%$ da oferta total anual.

A altitude média das cidades que representam essa mesorregião é a mais elevada dentre as estudadas, cerca de 1.100 metros. Ocorrem grandes oscilações na produção ao decorrer do ano e de ano a ano (Figura 4). Há menor oferta de couve-flor geralmente no período que vai

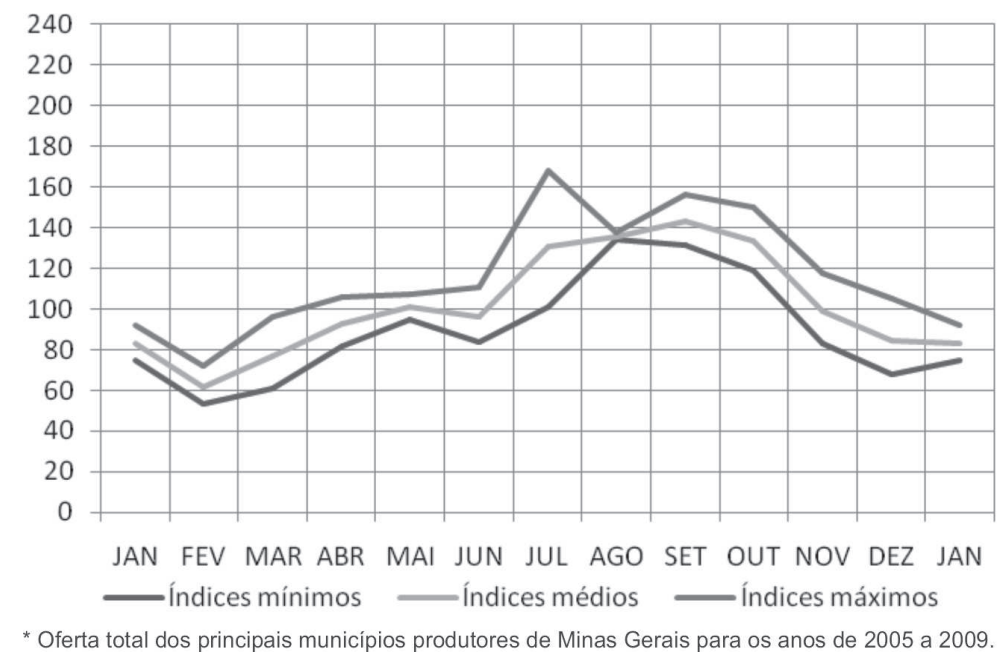

Figura 1. Índices estacionais mínimos, médios e máximos da oferta de couve-flor destinada às unidades da CEASAMINAS.

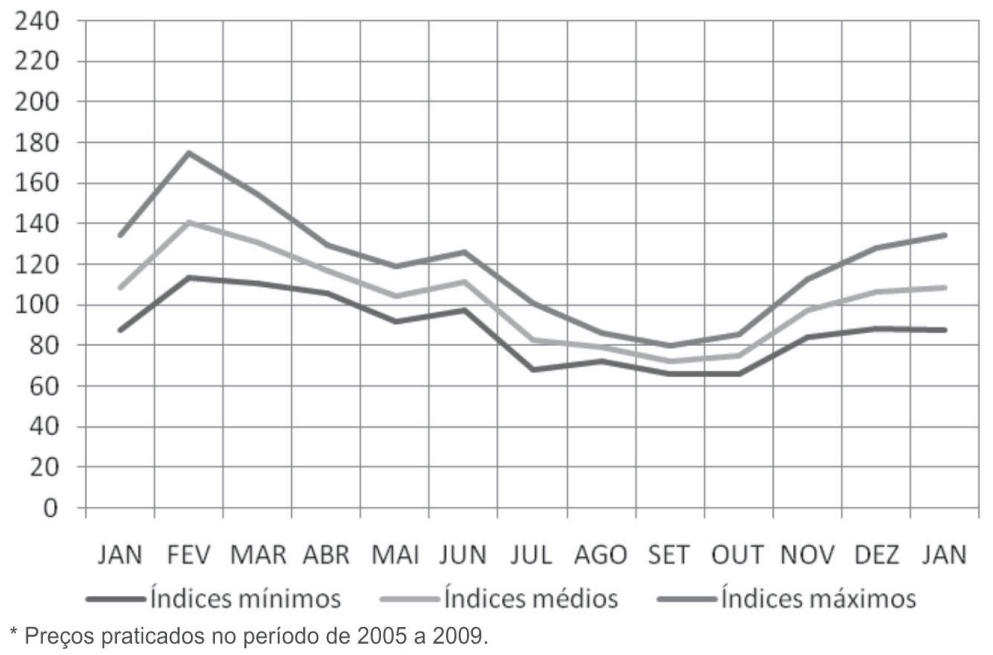

Figura 2. Índices estacionais mínimos, médios e máximos dos preços de couve-flor destinada à CEASAMINAS - Unidade grande BH. 
de dezembro até junho. Dezembro a fevereiro foram os meses de menor oferta nessa época, com maiores variações de ano a ano, principalmente em janeiro, com índice variando em 95 pontos entre os anos de menor e maior oferta (Figura 4). Esse período corresponde ao verão, com temperatura mínima típica de $14^{\circ} \mathrm{C}$, média de $21^{\circ} \mathrm{C}$ e máxima de $27^{\circ} \mathrm{C}$. Por se tratar de região de elevada altitude, é possível que em determinados anos quedas bruscas de temperatura ou excessos de precipitação nessa época sejam responsáveis por reduções de oferta devido ao menor número de cabeças comercializáveis.

Nos meses de setembro e outubro ocorrem as maiores produções, mas com grande variação de ano a ano, principalmente em setembro, com índice variando em 137 pontos entre os limites mínimo e máximo (Figura 4). Esse período corresponde à meia- estação, com temperatura mínima típica de $12{ }^{\circ} \mathrm{C}$, média de $18^{\circ} \mathrm{C}$ e máxima de $26^{\circ} \mathrm{C}$.
A instabilidade da produção de couve-flor em setembro/outubro pode ser atribuída à falta de adaptação dos principais cultivares à região nessa época: cultivares de inverno podem ser desfavoravelmente afetados em anos mais quentes, e a época é demasiadamente fria para o plantio de cultivares de verão.

Triângulo Mineiro: Essa mesorregião representa $9 \%$ da oferta total média destinada às unidades da CEASAMINAS (Tabela 1).

A altitude média das cidades produtoras que representam essa mesorregião é cerca de 860 metros. Ocorre menor oferta de couve-flor geralmente no período que vai de março a maio, principalmente em abril; março e abril são os meses nessa época de menor oferta com maiores variações de ano a ano, principalmente em abril, com 65 pontos de diferença entre os índices mínimo e máximo da oferta (Figura 5). Esse período de

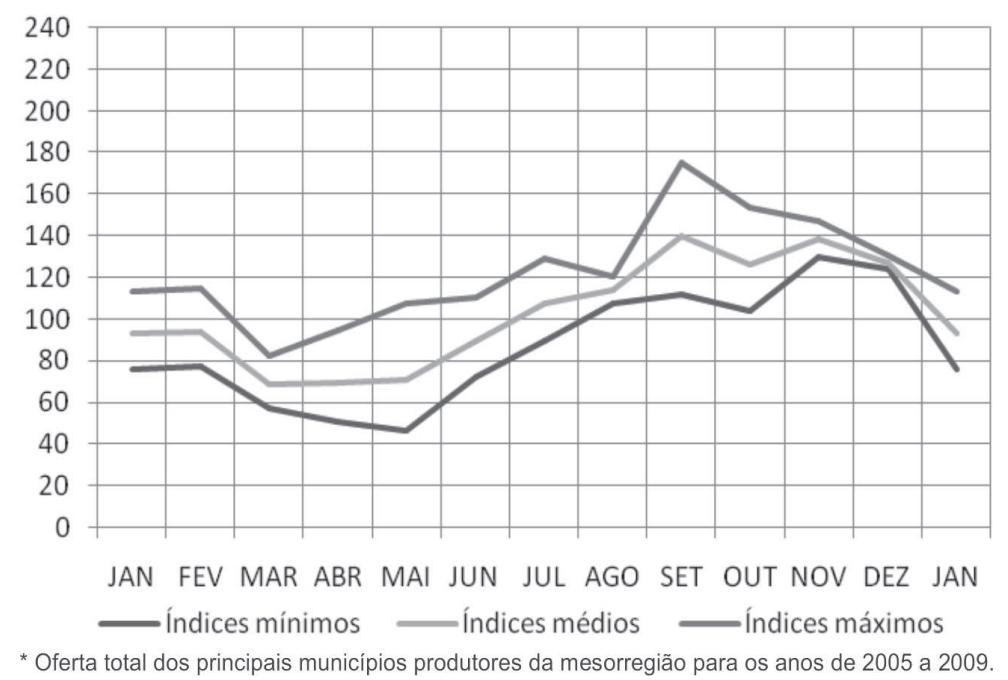

Figura 3. Índices estacionais mínimos, médios e máximos da oferta de couve-flor produzida na Mesorregião Metropolitana de Belo Horizonte destinada às unidades da CEASAMINAS.

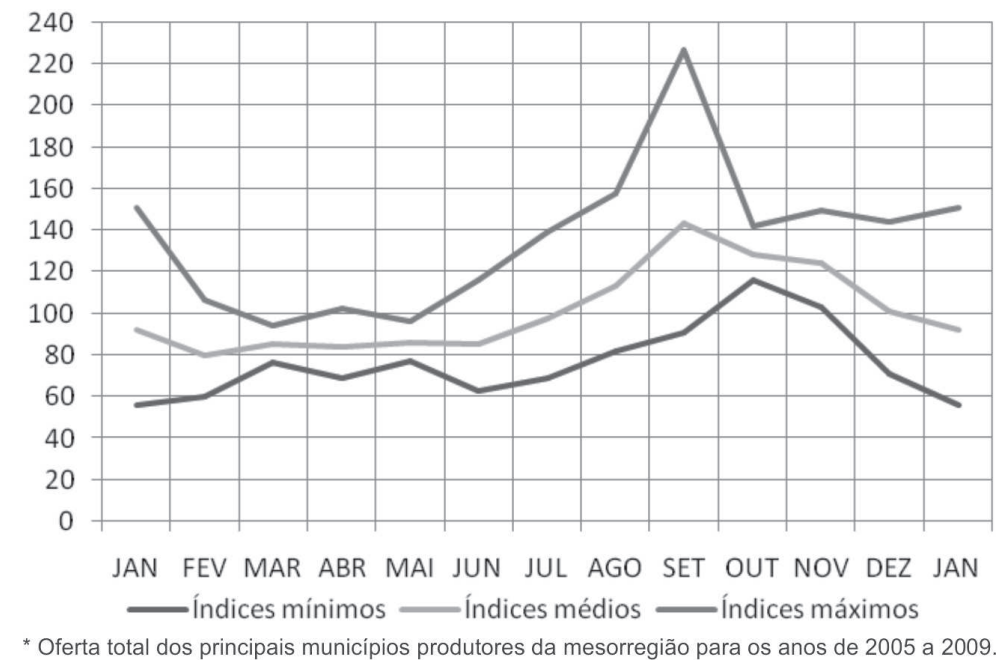

Figura 4. Índices estacionais mínimos, médios e máximos da oferta de couve-flor produzida no Campos das Vertentes destinada às unidades da CEASAMINAS.

Rev. Ceres, Viçosa, v. 61, n.3, p. 323-331, mai/jun, 2014 
menores ofertas corresponde à meia estação, com temperatura mínima típica de $18{ }^{\circ} \mathrm{C}$, média de $22^{\circ} \mathrm{C}$ e máxima de $26^{\circ} \mathrm{C}$.

Nos meses de agosto a outubro ocorrem as maiores produções, mas com grande variação de ano a ano, principalmente em setembro, com 88 pontos de diferença entre índices mínimo e máximo (Figura 5). Esse período de maiores ofertas corresponde ao fim do inverno/início de primavera, com temperatura mínima típica de $18^{\circ} \mathrm{C}$, média de $24^{\circ} \mathrm{C}$ e máxima de $30^{\circ} \mathrm{C}$.

A exemplo das regiões anteriores, também aqui são evidentes as dificuldades de produção nas meias-estações, isto é, nos períodos de transição verão/outono e inverno/primavera.

Vale do Rio Doce: Essa mesorregião representa em termos de produção média a menor oferta, cerca de $6 \%$ do total (Tabela 1).
A altitude média das cidades produtoras que representam essa mesorregião é de 700 metros, sendo a menor dentre as mesorregiões estudadas.

Ocorre menor oferta de couve-flor geralmente no período que vai de janeiro a abril. Março foi o mês dessa época com maiores variações de ano a ano, com índice variando em 71 pontos entre os anos de menor e de maior oferta (Figura 6). Esse período corresponde à meia-estação, com temperatura mínima típica de $18^{\circ} \mathrm{C}$, média de $23^{\circ} \mathrm{C}$ e máxima de $29^{\circ} \mathrm{C}$. Percebe-se que por ser uma região de menor altitude, o regime de temperaturas típicas de meia estação ocorre cerca de um mês antes das outras regiões.

A partir de maio, a produção sobe, atingindo a média (índice 100) e estabilizando-se nela até o mês de setembro, sendo agosto o mês nessa época de maior oferta em que ocorrem maiores variações de ano a ano, de 92 pontos entre os índices mínimo e máximo. Esse período

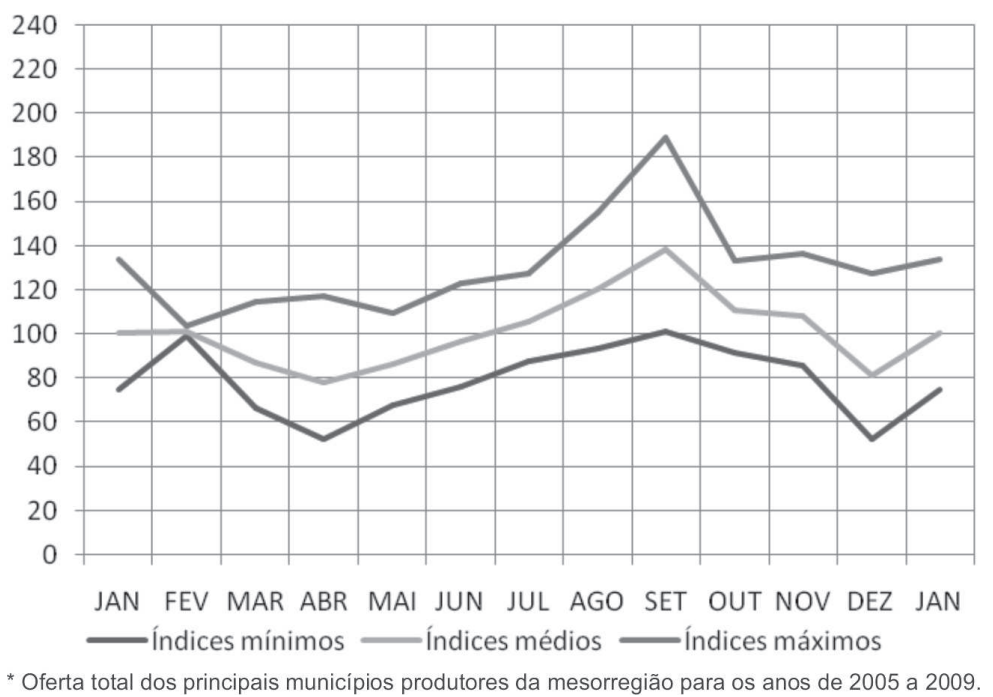

Figura 5. Índices estacionais mínimos, médios e máximos da oferta de couve-flor produzida no Triângulo Mineiro destinada às unidades da CEASAMINAS.

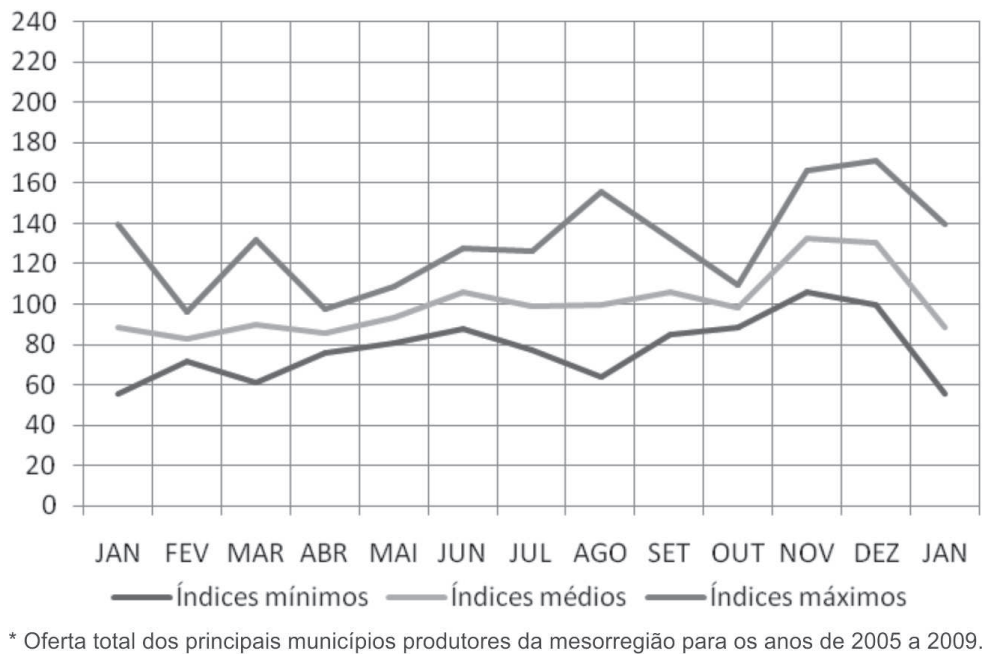

Figura 6. Índices estacionais mínimos, médios e máximos da oferta de couve-flor produzida no Vale do Rio Doce destinada às unidades da CEASAMINAS. 
corresponde ao final do inverno/meia- estação, com temperatura mínima típica de $14{ }^{\circ} \mathrm{C}$, média de $20^{\circ} \mathrm{C}$ e máxima de $26^{\circ} \mathrm{C}$.

Nos meses de outubro a dezembro ocorrem as maiores produções, mas com grande variação de ano a ano, principalmente em dezembro, com índice variando em 71 pontos entre os anos de menor e maior oferta. Essa grande variação estacional ocorre provavelmente em consequência das elevadas taxas de precipitação acumuladas nessa época do ano. Esse período corresponde à primavera, com temperatura mínima típica de $18^{\circ} \mathrm{C}$, média de $23^{\circ} \mathrm{C}$ e máxima de $28^{\circ} \mathrm{C}$.

A altitude média dos municípios produtores é superior a 700 metros, e nas três primeiras regiões produtoras, que representam conjuntamente $86 \%$ da produção total, é em geral superior a 800 metros.

O desenvolvimento adequado da cabeça na couveflor está ligado à produção em épocas de climas amenos (Filgueira, 2003); por isso, regiões nesssa faixa de altitude são, em geral, consideradas favoráveis para o cultivo de couve-flor ao longo do ano todo, desde que se plantem cultivares apropriados a cada estação do ano: para o verão predominam plantios de setembro/outubro, para colheitas em dezembro a fevereiro, enquanto para o inverno plantios a partir de abril/maio, para colheitas em geral de julho a setembro.

Mesmo nessas regiões consideradas favoráveis, fica evidente a existência de gargalos à produção. De modo geral, a produção tende a ser menor nos meses de verão, nos quais, apesar da existência de cultivares tolerantes ao calor, a precipitação excessiva pode concorrer para menores produções e, consequentemente, maiores preços (Figura 1). A situação torna-se crítica no período de transição entre verão e outono, em que a grande oscilação entre temperaturas diurnas e noturnas, típicas dos meses de abril e maio, pode prejudicar a produção, pela formação de cabeças pequenas, de pouco valor comercial. Essas oscilações de temperatura podem ser variáveis de ano a ano, o que explica a grande amplitude de variação de oferta ano a ano encontrada nos meses de abril/ maio, na Região Metropolitana de Belo Horizonte (Figura 3) e Triângulo Mineiro (Figura 5), e um pouco mais cedo (março) no Vale do Rio Doce (Figura 6).

Por outro lado, temperaturas amenas de inverno, associadas às baixas precipitações, tornam essa estação a mais favorável à produção, com maiores ofertas e menores preços (Figura 1) de julho a setembro. Contudo, mesmo nessa época, agosto no Vale do Rio Doce (Figura 6) e setembro nas demais três mesorregiões (Figuras 3, 4 e 5) são marcados por apresentarem grandes variações de oferta de ano a ano, evidenciadas pelas amplitudes de variação entre os índices mínimos e máximos. Por se tratar de épocas em geral de baixos preços médios (Figura 1), é provável que as variações de ano a ano possam refletir, em parte, os preços praticados em anos anteriores nessa mesma época, que possam ter influenciado a decisão do produtor quanto à área total a ser plantada no ano seguinte. Contudo, oscilações de temperatura entre dia e noite, comuns nessa transição entre fim do inverno e início de primavera, provavelmente constituem razões para essa instabilidade de oferta: cultivares de inverno plantados nessa época podem não apresentar comportamento adequado em anos em que as temperaturas sejam maiores do que as normalmente esperadas.

\section{CONCLUSÕES}

As variações estacionais de oferta refletem claramente as limitações dos cultivares atualmente disponíveis e a necessidade de novos cultivares que possam tolerar as grandes oscilações de temperatura nos meses de meiaestação, seja na transição verão/outono, seja na de inverno/primavera. Fica evidente que, a despeito da disponibilidade de cultivares de verão, a produção de couve-flor ainda é mais baixa nesa época do ano, um reflexo provável da alta precipitação que ocasiona maiores perdas por doenças na lavoura e em pós-colheita.

\section{AGRADECIMENTOS}

À FAPEMIG (Fundação de Amparo à Pesquisa do Estado de Minas Gerais), ao CNPq, à CAPES, UFLA, FAEPE e ao HortiAgro Sementes S.A.

\section{REFERÊNCIAS}

Araújo JLP, Correia RC \& Mangabeira MO (1999) Comportamento de Preços da Cebola na Região do Submédio São Francisco. Petrolina, EMBRAPA. 4p. (Boletim Técnico, 99).

Camargo-Filho WP \& Mazzei AR (1994) Hortaliças Prioritárias no Planejamento da Produção Orientada: Estacionalidade da Produção e dos Preços. Informações Econômicas, 24:9-54.

Camargo-Filho WP, Mazzei AR, Camargo AMMP \& Olivetti MPA (1994) Estacionalidade da Produção e Preços de Abóboras em São Paulo. Informações Econômicas, 24:25-37.

Carvalho PLC, Sáfadi T \& Ferraz MIF (2008) Sazonalidade nos Índices de Preços Setoriais Agrícolas do Município de Lavras, MG. Revista Brasileira de Biometria., 26:83-101.

CEASAMINAS (2010) Dados de preços e ofertas para os anos de 2005 a 2009. Disponível em: <http://www.ceasaminas.com.br/ informacoes_mercado.asp>. Acessado em: 22/2/2010.

CEPETEC/INPE (2010) Centro de previsão de tempo e estudos climáticos. Disponível em: <http://bancodedados.cptec.inpe.br/ climatologia/index.jsp>. Acessado em: 30 de maio de 2010.

Escola Superior de Agricultura "Luiz de Queiroz" (1987) INDEVES: Programa para cálculo de índices de variação estacional de preços. Departamento de Economia e Sociologia Rural da ESALQ/ USP. CD-ROM.

Filgueira FAR (2003) Novo manual de olericultura: Agrotecnologia moderna na produção e comercialização de hortaliças. Viçosa, Editora da UFV. 402p. 
Francisco VLFS, Pino FA, Sueyoshi MLS, César SAG \& Amaral AMP (1995) Sazonalidade em Séries Temporais Econômicas: Aplicações. Agricultura em São Paulo, 42:57-71.

Hoffmann R (1991) Estatística para economistas. 2aed. Piracicaba, Biblioteca Pioneira de Ciências Sociais. 426p.

Luengo RFA \& Junqueira AH (1999) Distribuição de Hortaliças no Brasil. Brasília, EMBRAPA. 7p. (Boletim técnico, 16).

Machado AG, Figueiredo RS \& Silva Júnior RP (2008) Variação Estacional dos Preços de Tomate Salada Comercializados no Ceasa-GO no Período 1999 a 2006. Informações Econômicas, $38: 20-27$
Maluf WR (2001) Heterose e Emprego de Híbridos F1 em Hortaliças. In: Nass LL, Valois ACC, Melo IS, Valadares MC (Eds). Recursos genéticos e melhoramento de plantas. Rondonópolis, Fundação MT. p.327-355.

May A, Tivelli SW, Vargas PF, Samra AG, Sacconi LV \& Pinheiro MQ (2007) A Cultura da Couve-Flor. Campinas, Instituto Agronômico. 36p. (Boletim Técnico IAC, 200).

Rezende JB, Castro ARC \& Starling MBL (1993) Os Problemas da Comercialização de Hortigranjeiros na Região Metropolitana de Belo Horizonte. Análise \& Conjuntura, Belo Horizonte, 8:43-56.

Spiegel MR (1993) Estatística. 3ªed. São Paulo, Makron Books. 640 p. 